\title{
Forest certification audit results as potential changes in forest management in Canada
}

\author{
by Megan Masters ${ }^{1}$, Anna Tikina² and Bruce Larson²
}

\begin{abstract}
An analysis of CSA, FSC, and SFI audit conditions was conducted identifying areas requiring operational changes to obtain certification. Audit reports for each standard differed in both number and focus of requirements. The FSC audits required more changes in environmental, social and economic themes, while CSA and SFI audit reports emphasized changes in management systems and aquatic ecosystems management. Although not a guarantee of changes in operations and management, the audit conditions point towards areas where forest certification can potentially have impacts on forest management.
\end{abstract}

Keywords: forest certification, standards, audit conditions, forest management

\begin{abstract}
RÉSUMÉ
Une analyse des conditions d’audit CSA, FSC et SFI a été réalisée pour identifier les domaines menant à la certification qui nécessitent des changements opérationnels. Les rapports d’audit de chaque norme se sont avérés être différents tant en terme de valeur atteinte que d’attention apportée à la norme. Les audits FSC ont nécessité plus de modifications au niveau des thèmes environnementaux, sociaux et économiques, tandis que les rapports d'audit CSA et SFI ont mis laccent sur les systèmes d’aménagement et de gestion des écosystèmes aquatiques. Même s’elles ne constituent pas une garantie des changements au niveau des opérations et de la gestion, les conditions d'audit identifient les points où la certification forestière peut possiblement avoir un effet sur l'aménagement forestier.
\end{abstract}

Mots clés : certification forestière, normes, conditions d’audit, aménagement forestier

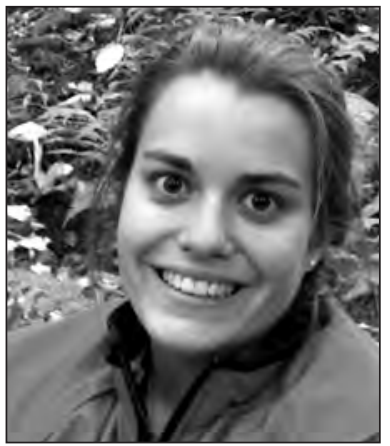

Megan Masters

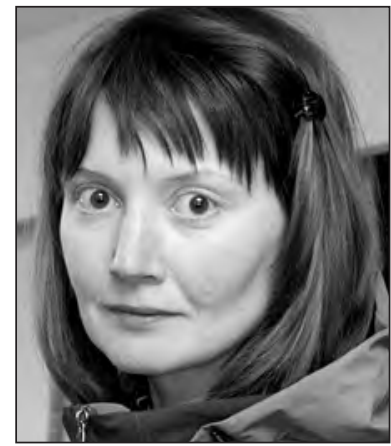

Anna Tikina

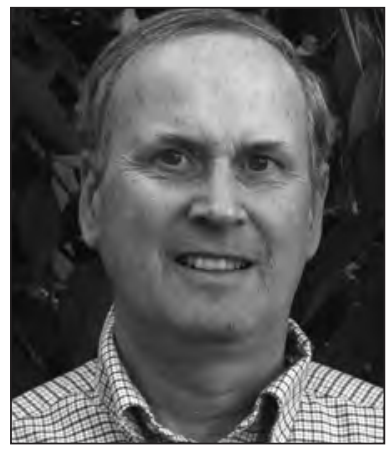

Bruce Larson

(CSA) CAN/CSA Z809 standard, the Sustainable Forestry Initiative (SFI) standard, and four regional standards developed under the Forest Stewardship Council (FSC). Some environmental non-governmental organizations (ENGOs) have raised doubts about the effectiveness of standards and certificates, claiming that forest management has not been modified during the process (Ozinga 2001). A few studies have countered this argument and examined theoretical

\section{Introduction}

Forest certification is becoming business reality for the forest industry in Canada (Abusow 2008). Certification processes intend to recognize good forest management and improve forest practices. Six forest management certification standards are available to the Canadian forest industry, each presenting different requirements. The most common forest certification standards, usually called Sustainable Forest Management (SFM) schemes, include the Canadian Standards Association

questions of the effectiveness of forest certification (Cashore et al. 2004, Leslie 2004, Gulbrandsen 2005, Tikina and Innes 2008), and various stakeholders' perspectives on certification effects (Klingberg 2003, Ozanne and Vlosky 2003, Vlosky et al. 2003, Kozak et al. 2004).

With each certification, forest companies go through a rigorous audit process to determine the readiness of the applicant to receive a certificate of compliance with the standard. The

\footnotetext{
${ }^{1}$ School of Resource and Environmental Studies, Faculty of Management, Dalhousie University, 6100 University Avenue, Suite 5010, Halifax, Nova Scotia B3H 3J5. Current address: National and Departmental Relations Division, Canadian Forest Service - Natural Resources Canada. E-mail: mmasters@nrcan.gc.ca

${ }^{2}$ Forest Resources Management Department, Faculty of Forestry, University of British Columbia, 2223-2424 Main Mall, Vancouver, British Columbia V6T 1 Z4.
} 
process presents three opportunities for forest management improvement: updating current operations to meet the requirements of the certification standard before the audit, further improvements resulting from a preliminary auditing process, and improvements introduced in order to clear a series of preconditions and conditions left for the company to complete prior to certification. In a study devoted to the analysis of FSC audit conditions and preconditions in the USA, Newsom et al. (2006) stated that if implemented, audit conditions present a potential for on-the-ground impact. Audit conditions and preconditions have not been studied in the Canadian setting, and this study contributes to closing this gap.

Public summaries of audit reports describe an application's strengths, weaknesses, non-conformances, and conditions to be met for certification. Clearing conditions and preconditions is mandatory for certification, while following recommendations is not. Any changes made by a company to obtain auditor approval for certification indicates an improvement promoted by certification. The objective of the study is to analyze SFI, FSC and CSA audit conditions and preconditions in Canada, and to investigate any areas of changes of forest management prescribed therein.

\section{Scope and Methods}

Among three possible points of introduced improvements into forest management, self-auditing results and pre-certification audit results are not publicly available, and they have been excluded from this study. This analysis covers only the third possibility for change connected with forest certification-audit conditions and preconditions. The companies listed as certified in the Canada Certification Report: June 2007 (Canadian Sustainable Forestry Certification Coalition 2007) were used as a guide for obtaining audit reports. Information presented relating to preconditions, conditions, and recommendations in the summaries were employed for the development of a database encompassing the CSA Z8092002, SFI 2002-2005 and 2005-2009, and all Canadian FSC standards (FSC Boreal Standard, 2004; FSC Maritime Standard, 2003; FSC-BC Regional Standard, 2005; and FSC International Standard used in lieu of not-finalized FSC Great Lakes - St. Lawrence standard). The audit dates ranged from 2000 to 2007 . The summaries were obtained through the use of the certification standards Web sites, auditing company Web sites, and forest management company Web sites. All non-conformances and areas of weakness were compiled into a database. This information was analyzed to determine adjustments to be completed by a company to obtain certification.

Four primary themes were selected to classify the information and facilitate comparison: environmental, economic, social, and management systems. These were further divided into 26 categories addressing specific goals (Table 1). The themes and categories were developed based on criteria and indicators used in forest certification standards.

Descriptive statistics were used to analyze the data. A standard-paired t-test with Tukeys Honestly Significant Differences was used to reveal differences between the standards in terms of quantity of the requirements. Preconditions were available only for thirty FSC audit reports, so a comparison of standards by the number of preconditions was impossible and was therefore excluded from the t-test analysis. The preconditions were analyzed with descriptive methods.

\section{Results and Discussion}

Overall, 130 audit reports were covered by the analysis. They reported the total of 1287 areas of improvement. The four major themes were analyzed to try to determine differences among the forest management standards currently used by the Canadian forest industry. All themes and categories were addressed by the standards. Reports for each standard covered some requirements, general for all standards, and also presented some unique conditions and recommendations. The conditions, preconditions and recommendations were analyzed by category and standard (Table 1, Fig. 1-4).

The preconditions in the FSC audit reports indicate the categories that receive most attention during the FSC audits. These are (High Conservation Value Forests) HCVFs and Protected Forests, and Forest Management and Planning (Table 1).

Although similar overarching themes were observed, audit reports for each standard had a different focus. The conditions and recommendations presented by the FSC audits were far more numerous and narrow in scope than those presented by the CSA and the SFI standards. The audit reports vary in scope and depth, reflecting the nature of each standard and its requirements. The areas of improvement are discussed by theme below. Conditions are mandatory for implementation and received more attention than non-obligatory recommendations.

\section{Environmental theme}

The broad and often vague conditions presented in the CSA audit reports parallel similarly broad requirements of the CSA standard, e.g., they call for maintaining water quality and quantity without specifying the means to achieve the objectives (CAN/CSA Z809-02 2002). Objectives and deliverables (indicators and targets) are set by the company, and define the "bite" of the standard (Potoski and Prakash 2005): easily achievable objectives turn certification into a bureaucratic procedure; stringent objectives indicate true leaders in the field. In contrast, the FSC audits dealt with more specific conditions, reflecting the specific nature of the FSC standard requirements. The FSC conditions far outnumber the other two standards with the exception of Category 1.9 (Carbon Requirements). The areas of improvement on carbon requirements were addressed solely by the CSA audits (Fig. 1).

The specific requirement of the FSC standard pertaining to HCVFs led to the fact that FSC recorded many more conditions and recommendations than the other two standards in the category HCVFs and Protected Forests. It is surprising, however, to find a very small number of areas of improvement for CSA and SFI in this category-smaller than, e.g., in Aquatic Ecosystems and Species with Specific Needs. For the FSC, HCVFs and Protected Forests is the category that received the greatest number of conditions and recommendations in the theme. This is a good representation of the specific nature of the FSC standards, which were developed with the conservation idea in mind (Cashore et al. 2004).

\section{Economic theme}

The economic theme was acknowledged in the SFI and FSC reports. The audit requirements differed in their focus. Six out of eight SFI audit conditions addressed Purchasing and Sales (Category 2.3). The FSC standards placed more emphasis on efficiency: 23 conditions and 18 recommendations were found in its Economic theme requirements (Fig. 2). 


\begin{tabular}{|c|c|c|c|c|c|c|c|c|c|}
\hline \multirow[b]{2}{*}{ Categories } & \multicolumn{3}{|c|}{ Preconditions } & \multicolumn{3}{|c|}{ Conditions } & \multicolumn{3}{|c|}{ Recommendations } \\
\hline & CSA & FSC & SFI & CSA & FSC & SFI & CSA & FSC & SFI \\
\hline \multicolumn{10}{|l|}{ Environmental theme } \\
\hline 1.1 Aquatic Ecosystems & - & 1 & - & 9 & 23 & 12 & 8 & 6 & 6 \\
\hline 1.2 Species with Specific Needs & - & 1 & - & 4 & 20 & 6 & 5 & 12 & 6 \\
\hline 1.3 Site Inventories and Data Collection & - & 0 & - & 0 & 12 & 1 & 4 & 10 & 3 \\
\hline 1.4 Exotic and Invasive Species & - & 1 & - & 0 & 5 & 0 & 1 & 3 & 0 \\
\hline 1.5 Chemical Management & - & 0 & - & 1 & 17 & 0 & 0 & 3 & 0 \\
\hline 1.6 Pest Management & - & 1 & - & 3 & 14 & 7 & 3 & 8 & 6 \\
\hline 1.7 $\mathrm{HCVFs}^{\mathrm{a}}$ and Protected Forests & - & 9 & - & 1 & 67 & 1 & 0 & 20 & 0 \\
\hline 1.8 Soil Conservation & - & 0 & - & 2 & 11 & 3 & 1 & 2 & 3 \\
\hline 1.9 Carbon Requirements & - & 1 & - & 2 & 0 & 0 & 3 & 0 & 0 \\
\hline Environmental theme total & $\mathbf{0}$ & 14 & $\mathbf{0}$ & 22 & 169 & 30 & 25 & 64 & 24 \\
\hline \multicolumn{10}{|l|}{ Economic theme } \\
\hline 2.1 Waste Reduction & - & 0 & - & 0 & 7 & 1 & 0 & 4 & 4 \\
\hline 2.2 Efficiency & - & 1 & - & 0 & 23 & 1 & 0 & 18 & 1 \\
\hline 2.3 Purchasing and Sales & - & 0 & - & 0 & 20 & 6 & 0 & 7 & 7 \\
\hline 2.4 Annual Allowable Cut & - & 0 & - & 0 & 7 & 0 & 0 & 3 & 2 \\
\hline 2.5 Funding and Support & - & 0 & - & 0 & 1 & 0 & 0 & 4 & 0 \\
\hline Economic theme total & $\mathbf{0}$ & 1 & $\mathbf{0}$ & $\mathbf{0}$ & 58 & 8 & $\mathbf{0}$ & 36 & 14 \\
\hline \multicolumn{10}{|l|}{ Social theme } \\
\hline 3.1 First Nations Relations & - & 2 & - & 1 & 58 & 0 & 7 & 53 & 1 \\
\hline 3.2 Safety and Training & - & 2 & - & 3 & 20 & 6 & 6 & 13 & 8 \\
\hline 3.3 Public Communication & - & 1 & - & 9 & 30 & 3 & 9 & 31 & 16 \\
\hline 3.4 Employment & - & 0 & - & 0 & 3 & 0 & 0 & 8 & 1 \\
\hline Social theme total & $\mathbf{0}$ & 5 & $\mathbf{0}$ & 13 & 111 & 9 & 22 & 105 & 26 \\
\hline \multicolumn{10}{|l|}{ Management systems theme } \\
\hline 4.1 Monitoring & - & 0 & - & 1 & 54 & 6 & 5 & 12 & 6 \\
\hline 4.2 Documentation and Reporting & - & 1 & - & 10 & 7 & 2 & 15 & 19 & 21 \\
\hline 4.3 Legal Obligations & - & 1 & - & 0 & 9 & 2 & 2 & 11 & 4 \\
\hline 4.4 Emergency Preparedness & - & 0 & - & 2 & 1 & 5 & 5 & 3 & 8 \\
\hline 4.5 Corrective Actions & - & 0 & - & 3 & 8 & 3 & 8 & 6 & 15 \\
\hline 4.6 Audits and Review & - & 2 & - & 10 & 13 & 10 & 36 & 23 & 11 \\
\hline 4.7 Forest Management and Planning & - & 7 & - & 7 & 35 & 2 & 6 & 21 & 8 \\
\hline 4.8 Oil and Fuel Management & - & 1 & - & 2 & 5 & 4 & 3 & 0 & 3 \\
\hline 4.9 SOPs ${ }^{\mathrm{b}}$ and Other Operational Procedures & - & 1 & - & 2 & 23 & 4 & 4 & 16 & 3 \\
\hline Management systems theme total & $\mathbf{0}$ & 13 & $\mathbf{0}$ & 37 & 155 & 38 & 84 & 111 & 79 \\
\hline Total by standard & - & 30 & - & 79 & 494 & 89 & 132 & 320 & 143 \\
\hline Totals & & 30 & & & 662 & & & 595 & \\
\hline
\end{tabular}

a"HCVF" denotes High Conservation Value Forest

b"SOP" denotes Standard Operating Procedure

Both the FSC and the SFI standards suggest a decrease in roadside slash and snags, and waste outputs.

The absence of improvement areas for CSA may indicate the lack of economic requirements in the standard, and lack of the specific economic objectives and targets set by companies. While the latter non-conformances may be picked up in other categories, e.g., in the Category 4.3 Legal Obligations or Category 4.5 Corrective Actions, the first option identifies a drawback of the standard.

\section{Social theme}

The CSA areas of improvement in this theme (Table 1 and Fig. 3) reflect the focus of the standard on public participation in forest management-Category 3.3 Public Communication indicates the most number of areas of improvement. FSC standard has a separate principle on Aboriginal rights, and it is not surprising that Category 3.1. First Nations' Relations received most conditions for FSC. The FSC audit reports presented 58 conditions in Category 3.1, which was the second largest number for all categories in the study-only Category 1.7 HCVFs and Protected Areas received more areas of improvement (67) for the FSC standard.

With regard to the Aboriginal matters, the CSA standard focused mainly on respecting treaty rights and enforcing no prejudices (CAN/CSA Z809 -02 2002). Although the SFI audit reports were less numerous than CSA reports in this Theme, the current SFI standard has a more extensive list of specific requirements than the CSA standard (SFIS: 


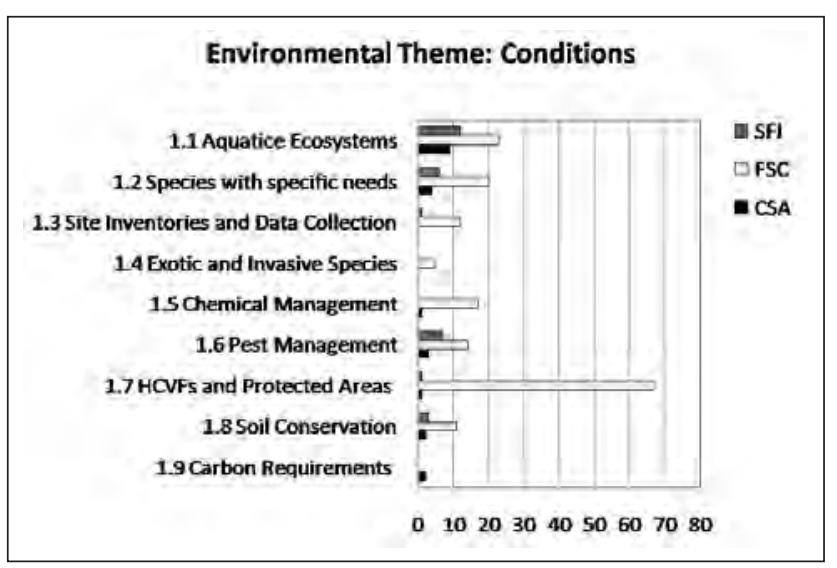

Fig. 1. The quantity of conditions in the environmental theme by standard.

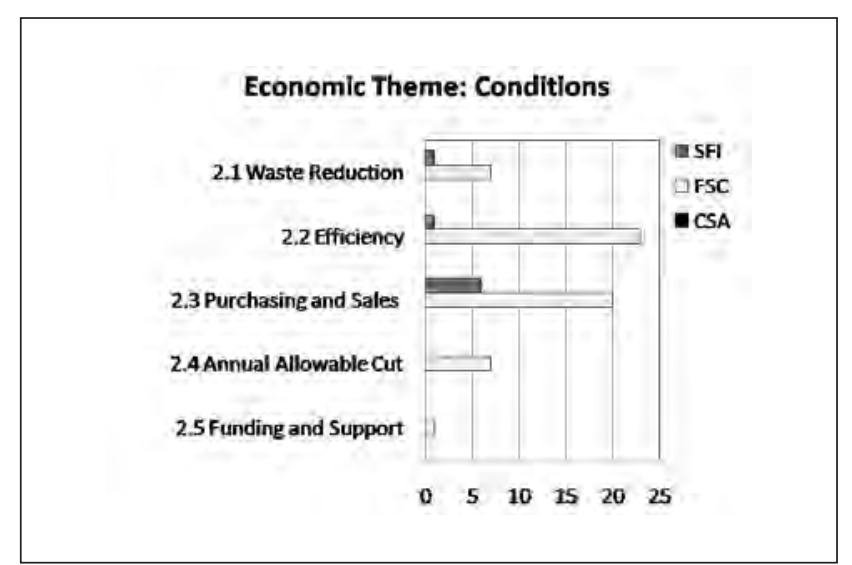

Fig. 2. The quantity of conditions in the economic theme by standard.

2005-2009 Standard 2004). While not too numerous, the number of SFI audit conditions was comparable to the number of SFI conditions in the economic theme.

\section{Management systems theme}

The management systems theme presents a much more varied set of conditions and recommendations (Table 1 and Fig. 4). Category 4.4 Emergency Preparedness is the only category where FSC audit reports showed a lower number of conditions than the other two standards.

Although the distribution is even, it should be noted that the overall numbers of conditions and recommendations for these categories are low in comparison with other categories. The CSA audits indicated potential changes in Category 4.6 Audits and Review and presented the greatest number of conditions in Category 4.2 Documentation and Reporting. The CSA standard is commonly compared to ISO 14001 requirements on management systems and its standard operating procedures (SOPs). However, the FSC quantity for Category 4.9 SOPs and Other Operating Procedures by far outnumbers the CSA areas of improvement.

Category 4.7 Forest Management and Planning received 35 FSC conditions, which also reflects the importance of the planning requirements for the FSC standards.

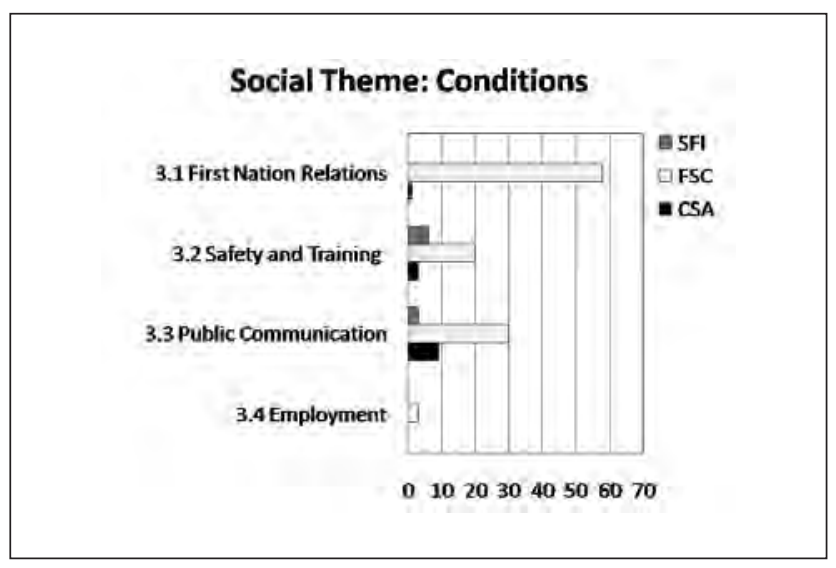

Fig. 3. The quantity of conditions in the Social theme by standard.

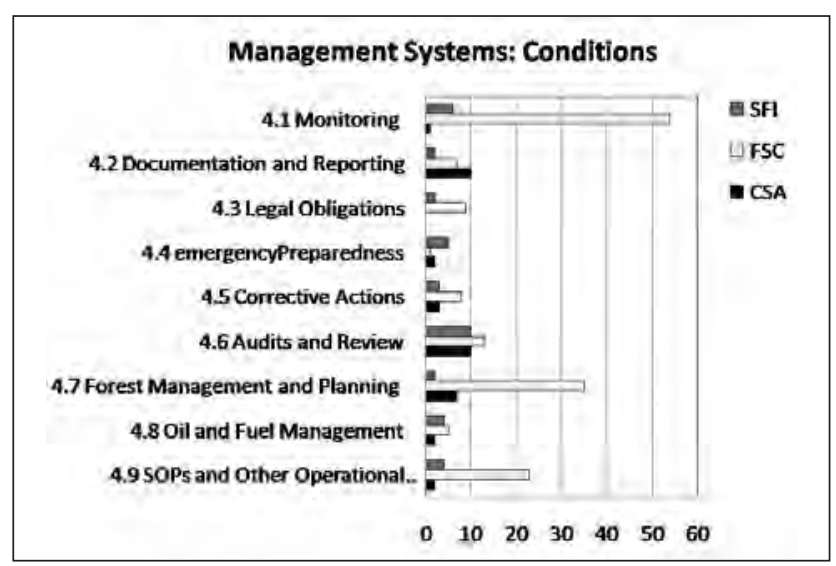

Fig. 4. The quantity of conditions in the management systems theme by standard.

\section{Differences among the standards}

Through the use of a t-test, the prevailing number of requirements in the FSC audits was found to be significantly different from both the CSA and SFI audits (Table 2). The CSA and the SFI standards do not differ significantly from one another for either quantity of conditions or recommendations.

The t-test indicates a significant difference among the number of conditions presented by FSC compared to those presented by the other certification schemes. These results imply that FSC certification standards introduce more changes, moving companies further towards the ultimate goal of SFM. However, this quantity of change is directly

Table 2. The differences in the number of conditions and recommendations by standard

\begin{tabular}{lcc}
\hline Standards Compared & $\begin{array}{c}\text { Conditions: } \\
\boldsymbol{p} \text { values }\end{array}$ & $\begin{array}{c}\text { Recommendations: } \\
\boldsymbol{p} \text { values }\end{array}$ \\
\hline CSA / FSC & 0.0000 & 0.0031 \\
CSA / SFI & 0.4259 & 0.6999 \\
FSC / SFI & 0.0003 & 0.0072 \\
\hline
\end{tabular}

${ }^{a}$ significant at $\alpha=0.05$ level 
linked to the quantity of requirements presented by the certification standards themselves. Although FSC outnumbers the other standards both in requirements pertaining to audit reports and certification standards, CSA and SFI standards, which appear to promote less change, are still considered adequate certifiers of SFM. These ideas invoke the question of which is better: quality or quantity. Some would argue that too many operating rules promoted by certification standards have negative affects on a company's bottom line and in turn, its competitiveness. It would then be suggested that all requirements be rigorously tested regarding their need in achieving SFM prior to their placement within a standard. However, the current periodic review process of certification standards, which includes the input from a range of stakeholders, originated from the response to this concern. As certification standards are reviewed and changed there is a trend indicating a convergence in their requirements (Cashore et al. 2008); as such, the specificity of the certification performance requirements may serve as an indication that companies are on their way to SFM.

What complexity is needed to ensure the needs of SFM are met? Although this question is becoming more predominant in the realms of certification, it cannot be addressed solely through the assessments of audit reports. Further research regarding the requirements of each certification system and their relative importance would be required. Despite the study's inability to assess the system's complexity, it is able to state that the current certification system can promote change within companies seeking to achieve SFM.

Several precautions should be taken in interpreting the results of the study. First, it should be emphasized that the study was performed with public information only. If conditions from pre-certification audits were analyzed, results may have been altered: pre-certification audits often impose many conditions that the company needs to fulfill prior to attempting a certification audit. However, as information regarding pre-audit conditions is typically private, it was not available for analysis.

Second, companies tend to pursue certification when their practices are already advanced (Hayward and Vertinsky 1999, Newsom et al. 2006). This also limits the number of the improvement areas found in certification audit reports, but in no way characterizes the standard scope or auditing methods. Thus, it is not possible to make conclusions on the stringency of the standard based on how many or how few conditions were found in audit reports. The methods of auditing and reporting vary by certification standards and by auditing company. It is possible that the standards receiving a lower number of conditions and recommendations reflected a difference in the auditing process of individual companies. The low number of reported areas of improvement does not, however, present a ground for comparing the quality of auditing. At the time of the study, QMI and KPMG usually audited compliance with the SFI and CSA standards, while SmartWood, SCS, SGS and Qualifor were used for FSC certification.

Not all conditions are similarly critical for obtaining or maintaining certification. While a forest company can focus on improving the areas where a failure will preclude certification (e.g., for a critical indicator in FSC), other areas for improvement noted in the audits do not get similar attention or the actions may be postponed. It is impossible to conclude that every area of improvement has the same probability of introducing change, but each definitely presents a potential for change.

Although altering attention paid to areas of improvement noted in audit reports is difficult to amend, some potential changes could affect other precautions mentioned above. Allowing public access to pre-audit conditions would provide increased knowledge regarding the extent to which certification standards promote positive change towards SFM. Secondly, encouraging all certification standards to be audited by one auditing company would help eliminate the inconsistencies associated with multiple auditors. These changes to the system, although somewhat logical for the improvement of this study, are not without consequence and integration is not recommended.

\section{Conclusions}

This analysis of Canadian CSA, FSC and SFI audit requirements was conducted to identify the areas that mandate operational change to comply with the standards. Audit reports for each standard differed in both quantity and quality of requirements. The FSC audits required a much greater number of conditions and recommendations than the other two standards. The FSC standard required more changes in all themes (environmental, social, economic, and management systems). While the CSA audit reports imposed conditions that are unique to the standard (e.g., carbon requirements), no unique areas of attention were found for SFI. If implemented, the audit conditions indicate areas where forest certification can improve forest management in Canada.

\section{References}

Abusow, K. 2008. Certification summary. Canada-wide - SFM July08 2008. Canadian Sustainable Forestry Certification Coalition. Canadian Sustainable Forestry Certification Coalition. 2007. Certification status report: Canada-wide - SFM - June 21, 2007. Abusow International Ltd.

Cashore, B., G. Auld, J. Lawson and D. Newsom. 2008. The future of non-state authority in Canadian staples industries: Assessing the emergence of forest certification. In K. Brownsey and M. Howlett (eds.). Canada's Resource Economy in Transition: The Past, Present, and Future of Canadian Staples Industries. pp. 209-232. Emond Montgomery Publications, Toronto, ON.

Cashore, B., G. Auld and D. Newsom. 2004. Governing through markets: forest certification and the emergence of non-state authority. Yale University Press, New Haven, CT. 320 p.

Gulbrandsen, L.H. 2005. The effectiveness of non-state governance schemes: a comparative study of forest certification in Norway and Sweden. International Environmental Agreements: Politics, Law and Economics 5(2): 125-149.

Hayward, J. and I. Vertinsky. 1999. What managers and owners think of certification. J. For. 97: 13-17.

Klingberg, T. 2003. Certification of forestry: a small-scale forester perspective. Small-scale Forest Economics, Management and Policy 2(3): 409-421

Kozak, R.A., D.H. Cohen, J. Lerner and G.Q. Bull. 2004. Western Canadian consumer attitudes towards certified value-added wood products: an exploratory assessment. Forest Products Journal 54(9): 21-24.

Leslie, A.D. 2004. The impacts and mechanisms of certification. International Forestry Review 6(1): 30-39. 
Newsom, D., V. Bahn and B. Cashore. 2006. Does forest certification matter? An analysis of operation-level changes required during the SmartWood certification process in the United States. Forest Policy and Economics 9(3): 197-208.

Ozanne, L.K. and R.P. Vlosky. 2003. Certification from the U.S. consumer perspective: A comparison from 1995 and 2000. Forest Products Journal 53(3): 13-21.

Ozinga, S. 2001. Behind the logo, an environmental and social assessment of forest certification schemes. FERN, Moreton-inMarsh, UK. 60 p. Available at http://www.fern.org/sites/fern.org/ files/Behind\%20the\%20logo.pdf.
Potoski, M. and A. Prakash. 2005. Covenants with weak swords: ISO 14001 and facilities' environmental performance. Journal of Policy Analysis and Management 24: 745-769.

Tikina, A.V. and J.L. Innes. 2008. A framework for assessing the effectiveness of forest certification. Canadian Journal of Forest Research 38(6): 1357-1365.

Vlosky, R.P., R. Gazo and D. Cassens. 2003. Certification involvement by selected United States value-added solid wood products sectors. Wood and Fiber Science 35(4): 560-569. 